\title{
Energy and industrial tourism: a specific niche on the tourism market
}

\author{
Natalya Alekseeva ${ }^{1 *}$, Katarina Hercegová ${ }^{2}$ \\ ${ }^{1}$ Volga Region State University of Service, Gagarina str. 4, 445017 Togliatti, Russian Federation \\ ${ }^{2}$ Prague Business School, Werichova str. 1145/29, 15200 Prague, Czech Republic
}

\begin{abstract}
Energy tourism belongs to the not-so-well-researched fields of tourism. Being a part of the industrial tourism or a special interest tourism, this type of tourism includes visits to the energy facilities and locations such as factories, mines, power stations and renewable energy sites. This paper describes the niche of the energy tourism within the tourism market and assesses its potential. We show that sometimes the energy tourism might intervene with dark tourism (for example, in the case of the tourist visits to the site of the Chernobyl nuclear power station). In addition, we show that this type of tourism is closely correlated with the public and social acceptance of traditional and renewable energy facilities. We conclude that this might be a promising and emerging type of tourism that will likely grow due to the ongoing industrialization and expenditure of energy-generating facilities envisaged for meeting the growing demand for energy all around the world.
\end{abstract}

\section{Introduction}

Nowadays, sustainable tourism is a fast-growing industry that seeks to protect tourism industry objectives and reduce the impact on the environment and local culture $[1,2]$. Demographic changes, such as an ageing population and growing children, are making themselves felt in the special-interest tourism (SIT) market [3]. In addition, digital tourism is also becoming an important issue, especially nowadays when the travel is disrupted by the COVID-19 pandemic $[4,5]$. Tourists can visit some unusual and extraordinary places while using web-based interfaces and programmes, reducing the need for traditional travel and the use of fossil fuels and other forms of energy. This reduces the travel costs and environmental impact of the tourism industry $[6,7]$.

There are many types of special tourist interests, but tourism of special interest will continue to gain in importance as tourists become people who want to experience and experience traditional mass holidays instead of traditional "mass holidays" [8]. A special tourist interest can take the form of a special event, such as a visit to a national park or even a trip to the local community. Another example are the Antarctic tourism products, followed by the general management problems and problems faced by small tourism businesses in Antarctica and beyond. In order to study the special-interest tourism in general and energy and industrial tourism in particular, we must first discuss the nature of tourism and its

\footnotetext{
*Corresponding author: natali0174@mail.ru
} 
variants. Travel of special interest is travel for people who go somewhere because they have a particular interest that can be pursued in a particular region or destination [9].

With regard to the above, one can take a look at energy tourism which is often considered a form of tourism of particular interest, but it is not the only form [10]. In general, demand in any SIT is expected to rise as tourist groups shrink. The adaptations already implemented by the travel and tourism industry allow for an expansion of the SIT and allow for the overall planning and development of travel experiences in these hubs.

In the Figure 1 that follows, one can see the photo of the Cheboksary Dam on Volga river which is a part of the Volga-Kama Cascade and the only hydro power station in the world that has a highway built over its roof. The dam is a local tourist attraction visited by thousands of people every year [11].

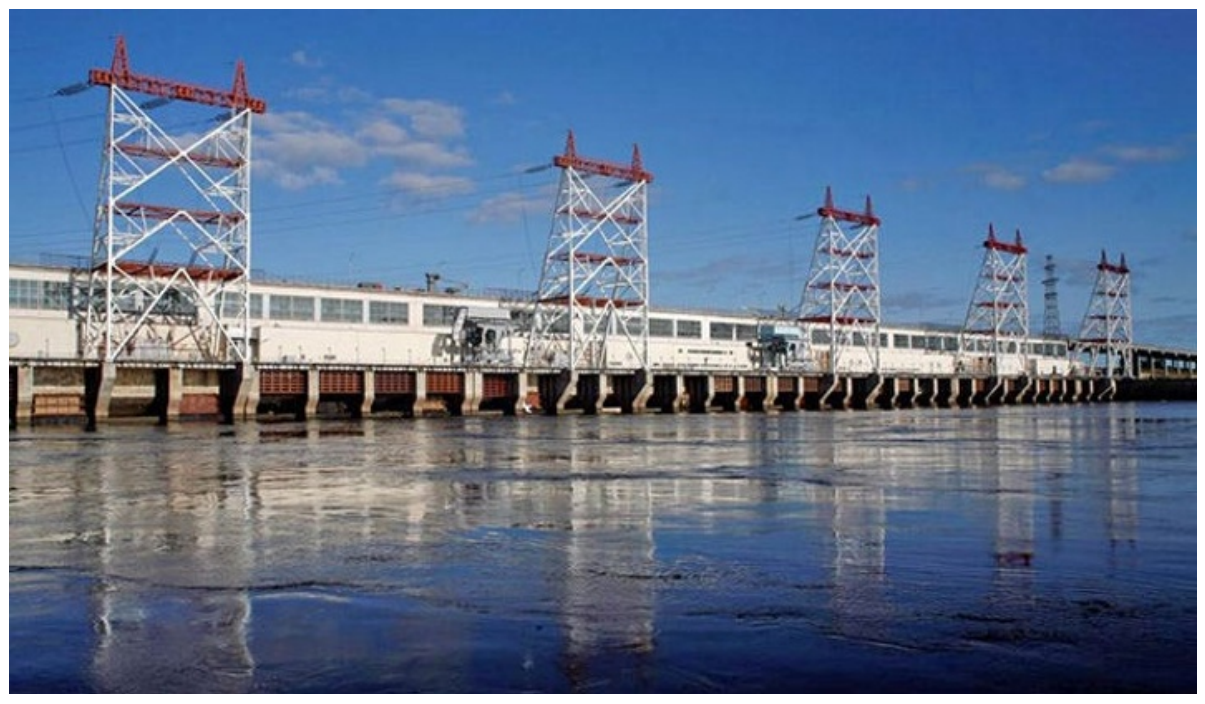

Fig.1. Cheboksary Dam on Volga river in Russia

With the remarkable increase in responsible travel decisions, the demand for tourism with special interest (such as energy tourism) is likely to increase. In fact, more and more individual travellers are being accompanied on their personal journey to various destinations that are less travelled and are not marked by mass tourism. They are run by local experts, such as experts in the field of energy tourism and energy saving. The World Travel and Tourism Council said that members of the tourism industry have improved their carbon efficiency by almost $20 \%$ in the last decade. With the aim of promoting sustainable tourism, the World Tourism Organisation (WTO) and the International Energy Agency (IEA) announced this year the launch of a new sustainable tourism strategy for the 2030s [12]. The development of the energy tourism as a special niche tourism opens up the possibility of focusing on sustainable energy and energy - efficient travel options such as renewable energy represented by the wind, hydro and solar energy [13]. There are also challenges for destinations that have to cope with a sudden and unplanned influx of visitors, such as hotels, restaurants, hotels and hotels.

The development of specialised types of tourism must be properly planned to ensure the long-term viability of the destination and the sustainability of its economy, and to maximise the benefits of this objective through sustainable local economic activity $[14,15]$. The opportunities to start a business in the tourism sector are plentiful and can often start with minimal investment. The establishment of a tourism company is particularly attractive as 
these companies are usually locally owned and offer more economic advantages than chain stores. If the goal is to generate more external revenue for the local economy, it is a viable strategy to expand, retain and establish businesses that manufacture, sell and provide services to tourists. The expansion, retention and creation of tourist businesses can also be a viable strategy, especially when the company manufactures, sells or provides services for products. Young people with a lot of energy can start bicycle taxis, become fishing guides, take tourists on kayaking adventures or start restaurants. Improved waste management should help tourism companies save money, create more jobs and make the destination more attractive. Sustainable tourism also refers to tourist activities that are and can be sustained indefinitely. Therefore, specific forms of tourism are not the only form of sustainable tourism, but rather they can strive to be more sustainable. This means that ecotourism should strive to protect the environment through the use of renewable energy sources such as wind, solar, water, geothermal and hydroelectric power [16]. This is embedded into the Sustainable Development Agenda 2030 which goals are closely directed to tourism (and energy tourism) development.

Tourism trends of particular interest are driven primarily by the increasing demand for energy tourism in the countries such as the USA, Canada, Australia, and New Zealand. Such developments and initiatives will have a significant impact on the emerging tourism of particular interest in these countries and in other parts of the world. Particular interests also promote the development of renewable energies as a key element of their tourism strategy. Some researchers predict that energy tourism as a part of adventure and industrial tourism will emerge as the fastest growing niche tourism [17]. Within this context, it is useful to define the place of energy tourism withing tourism studies, as a special part of the specialinterest tourism: it can be placed in the intersection of the adventure tourism and industrial tourism (see Figure 1).

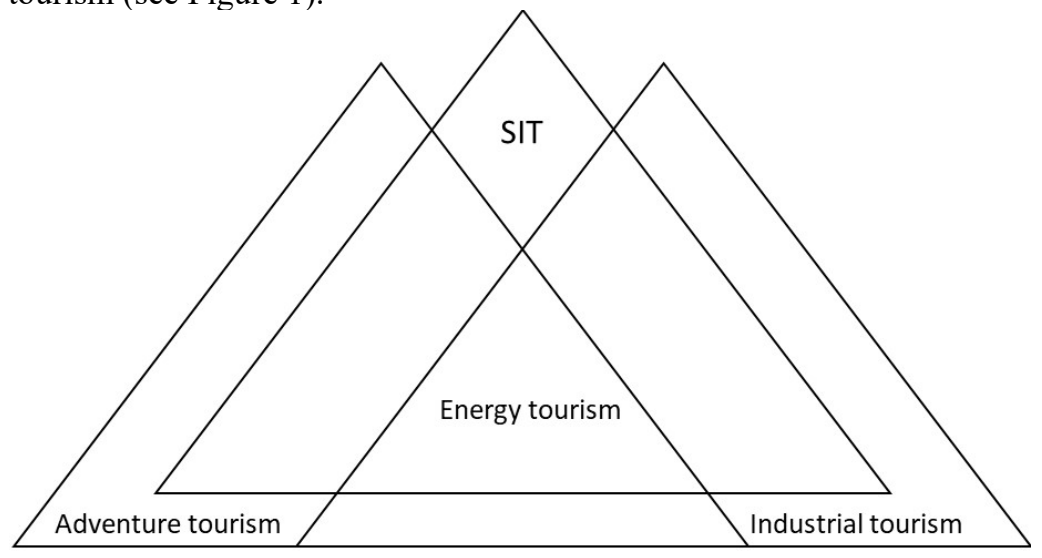

Fig.2. The place of energy tourism within the tourism industry

Moreover, tourism will by nature constitute the bulk of the tourism market in the coming years, with a steady growth rate after the massive vaccination that would help to eradicate the COVID-19 pandemic for good.

Therefore, one can say that energy tourism as tourism of particular interest would definitely have some impact on the tourism industry and the world economy. The tourism industry is one of the founders of plans to protect and preserve the environment and has played a decisive role in drawing attention to important environmental issues. Indeed, it is appropriate to promote the promotion of conservation and the conservation of natural resources in the world's major tourist destinations, such, for example, the Great Barrier Reef or Antarctica. 
The aim of this paper is to introduce the energy tourism as a part of special-interest tourism and as new and exciting field of tourism. The paper focuses in the links between tourism and energy, social acceptance of the energy tourism objects and the issues of niche tourism. It concludes with the description of outcomes and policy implications that might be relevant for tourism specialists, stakeholders and policymakers.

\section{Links between tourism and energy}

In addition to the economic benefits resulting from lower energy costs, the switch to renewable energy can strengthen sustainable tourism marketing strategies that increase tourist arrivals and enable higher hotel prices [18].

In addition to recognizing the benefits of renewable energy sources, it has to be acknowledged that energy saving and efficiency are critical to unleash the availability of energy for the future. Although no infrastructure has been built, wind power appears to be a potential source of electricity that is almost zero-emission and requires less energy than traditional forms of power generation, compared to traditional energy sources such as coal, natural gas, and nuclear power. A well-run renewable energy source - locally and operated such as wind, solar or geothermal energy can be supported, according to the report, as can traditional fossil energy sources. However, many studies have documented the negative impact of fossil fuels on tourism in the United States, including the impact of coal, natural gas and nuclear power on the environment and the economy [19].

The potential damage to tourism is often cited as one of the economic arguments against the planned development of environmental groups that are fighting against the development of wind farms in their areas, which they consider inappropriate due to the high landscape and natural value. Some studies suggest that the impact of the use of fossil fuels on tourism in the United States can be negative with overlaps into the economy and tourism. By planning tourism development in advance and avoiding the possible negative effects of energy sources on tourism in the tourist area, harmful and expensive mistakes can be avoided. The key message would be the impact of tourism on the environment, tourism and the local economy in a tourist area. Cleaner production techniques can be one way to minimise the environmental impact of tourism facilities [20].

In addition, tourism has been documented to have a positive effect on climate change, while some researchers pointed out that it has a negative impact on climate change. Some results might lead us to conclude that the tourism sector is one of the most important sources of carbon emissions in the global economy. They propose a unique model that analyses the relationship between tourism and energy consumption and carbon dioxide (CO2) emissions [21]. It turns out that growth in both tourists and tourism leads to a development in carbon emissions and vice versa. All three variables are significantly affected by changes in tourism, but to a greater extent. There is no doubt that tourism is an important source of economic growth, and an increase in tourist pollution will lead to business considerations that consume less energy. The literature has highlighted the importance of reducing pollution and documented that tourists can take effective measures, including reducing the use of fossil fuels and air pollution, as well as developing business considerations that consume less energy.

The above-mentioned literature shows that, although the importance of tourism has only recently been recognised, the existing study results are still in flux and cannot be generalised. This means that economic growth depends exclusively on tourism activities and that the $\mathrm{CO}_{2}$ emissions will be significant if tourism activity is not taken into account. World economies will not only be free of pollution, but also the state will experience frequent economic cycles due to the number of tourists in each period. Therefore, it seems important to investigate the relationship between tourism and energy consumption in the world economies as well as the 
environmental impact of tourism. In addition, it might be useful to explore the ecological Kuznets curve (EKC), as far as it provides a model for how growth and development should be reduced to overcome pollutant emissions [22]. In view of the ambitious policy objectives aimed at improving the quality of the environment and reducing carbon emissions, we will examine the link between tourism and energy consumption in small island economies and the environmental impact of tourism. In addition, one needs to investigate how the introduction of renewable energy will affect $\mathrm{CO}_{2}$ emissions world economies, by testing the effects of greenhouse gas emission reduction (GHG) targets which can be tested by comparing energy consumption and carbon dioxide emissions from small island economies. The tourism sector is highly dependent on the energy sector and energy-intensive, as the literature to date shows. The sector includes, but is not limited to, accommodation and lighting that consume a lot of energy. The link between energy consumption and accommodation has been confirmed by studies, but there is no study yet to confirm it. With regard to the above it might be worth investigating the relationship between the energy consumption of accommodation and the energy consumption in the tourism sector in Europe. The growth hypothesis based on tourism estimates the energy consumption of the tourism sector in Europe over the last 20 years and in the future. The "tourism leads to growth" hypothesis underestimates the impact of tourism on the energy consumption of the European energy sector. The energy consumption of tourism growth creates jobs and contributes to the concept of a sustainable future [23]. There is a remaining question whether energyconsuming tourism and growth contribute to creation and employment, as a blueprint for a sustainable future. Such tourism towards energy flow would offer a wide range of perspectives, including the creation of new jobs in the tourism sector and a reduction in greenhouse gas emissions. This would bring with it the increased greenhouse gas emissions associated with tourism and the energy sector. One facet of energy consumption is economic growth, as carbon emissions are linked to its sustainable efforts. Thus, combating tourismrelated carbon emissions towards energy flows (greenhouse gas emissions) requires a balance between the need to protect the environment and the economic and environmental benefits of tourism and energy [24].

\section{Social acceptance of energy facilities}

Studies have shown that the local context is important when discussing the acceptance of renewable energy sources $[25,26]$. It is not enough to assess the general attitude towards renewable energy by drawing conclusions about whether there will be local resistance to new projects. Therefore, a study on public attitudes towards the proposed projects of solar power plants can contribute significantly to developing a better understanding of the attitude of local people towards new energy projects in the region. The debate, coupled with long-standing economic pressure to reduce other countries' dependence on energy, has drawn attention to the importance of renewable forms of energy, including solar and wind [27].

It is therefore an important step to learn public attitudes to renewable energy projects in different parts of the world in order to understand the challenges that energy planners and governments face to varying degrees in implementing sustainable energy programs. The United States is ticking over and producing more energy from fossil fuels, but it is ticking over to renewable energy sources like wind and solar [28].

This approach is in line with the island's goal of becoming self-sufficient in energy - based on wind, solar or bio-energy - and making transport (including transport) more efficient and independent of oil and natural gas. For example, in Normandy, a joint wind farm development scheme was set up with the local authorities of the town of Le Havre, France. This facility allows municipalities to take on an energy source and to benefit financially from the wind farm by paying dividends to the municipality [29]. 
Approaches such as this can go a long way towards overcoming these problems by giving local authorities and citizens a voice and contributing financially to the success of the project. The fact that this ground-breaking law was developed and adopted with significant support from stakeholders and stakeholders underlines the importance of public participation in the efficient development of renewable energy. As the state tries to get the economy back on track to overcome the COVID-19 crisis, the restart of renewable energy development will play a key role. The law accelerates this by creating a new site process specifically designed for renewable-energy plants at a time when people need it most. The existing energygeneration process is designed to build fossil-fuel power plants - and create a nation - that will lead the way in clean energy and environmental protection. With this regard, the Swiss energy system had to be successively restructured after the financial crisis in 2008 and the collapse of its oil and gas industry. From this perspective, the Federal Council has developed a new strategy for the development of new energy facilities based on a revised energy perspective [30].

All of this is accompanied by new challenges with regard to the public and social acceptance of the use of renewable energies in public buildings and facilities. Scenario analyses suggest that renewables will probably be able to meet half of the world's electricity demand by 2050 . Future use of renewable energy depends on many factors, including the use of competing energy technologies such as wind and solar, and the development of new energy efficiency technologies. Along with costs, public acceptance is a key factor in the development of new renewable energy plants such as wind and solar. Clashes with local communities have been a major obstacle to the use of renewable energy - energy installations in many places, especially in rural areas. Arguments against wind power include the belief that it is inefficient and too expensive, and concerns about its environmental impact.

In countries all over Europe, wind planning and site decision-making processes are facing considerable challenges. It is important that such developments take place at a local level and that the residents of the wind farm sites are aware of their local wind farms. The social acceptance of wind power is therefore leading to an increasing number of visible site decisions at the local level. This affects both supporters and opponents, but in some European countries the planning and location process is facing considerable challenges.

\section{The importance of niche tourism in tourism industry}

As the world evolves, the landscape of the tourism industry is constantly evolving, only to make it more complex and complex. Niche tourism introduces the concept of tailoring specific tourism aspects to the needs of a market segment that is interested in something special and special. The concept focuses on how the experience for tourists can not only be customized, but also tailored to these needs and be more relevant to their specific needs and needs [31]. This is used by niche market tourism to focus visitors on a very specific market segment built around a well-defined product. It is only useful if the visitor throws everything - but - the kitchen - and plans a holiday that directly corresponds to his interests. Tourists today travel to a number of destinations to find opportunities that suit their passions. Shopping has gone from a complementary activity for tourists to a very relevant motivator and is a key factor in choosing a destination. Therefore, the niche markets in tourism are a great way to increase visits to destinations. This includes, but is not limited to, shopping malls, restaurants, hotels and hotels and can be tapped in a number of different ways, such as through the use of social media, online shopping and social networks.

One can see that in a globalized world of increasing equality, niche tourism represents diversity and a way to mark differences, according to a recent study by the Canadian Tourism Association (CTA). In image design, niche tourism destinations help to differentiate themselves through tourist products and to compete with the mass tourism market such as 
hotels, restaurants, hotels and hotels. The contribution of academic knowledge and understanding in this area is summarized in a recent article in the Journal of the Canadian Tourism Association (CCTA) by Professor David Smith from the School of Tourism and Tourism Management at the University of Toronto [32]. A turning point in Canadian tourism history from the early $20^{\text {th }}$ century to the present has attracted mass tourism to a variety of destinations, not only in terms of the tourism product, but also in terms of the culture and culture of tourism. The work of the academic community has advantages, but research is primarily focused on image design research, which illustrates the role of niche destinations in the marketing of tourism products. The practical benefits of this work for the industry include the ability to position and target their products in their niche markets and the development of new marketing strategies for niche destinations. The analysis also shows that the sale and promotion of culinary tourism has become a real niche market.

According to the majority of experts, gastronomic tourists combine the culinary experience with a visit to the surroundings of the destination through cultural routes, followed by wellness activities, themed events and shopping. In addition, the visit to markets, shopping, restaurants and hotels are among the most interesting activities for gastronomic tourists [33]. While art tourism is growing in the distance, it has become a niche aspect of travel and is summarized under the term cultural tourism.

Overall, niche tourism observes that people travel to a destination to practice art - related activities such as special events related to sports, art, dance, books and festivals. Tourists choose their destinations more for relaxation and reflexology and special massages. Global market trends indicate that tourism and tourism in the neighbouring countries of Asia, Africa, Latin America and the Middle East are some of the emerging tourist areas [34]. Geographically, there is significant growth in the tourism industry in Asia, Africa, Latin America, and the Middle East and Africa. The average age of international tourists has fallen and represents a growing segment of young tourists who are travelling to take a break from an increasingly stressful professional life. Niche tourism is mainly aimed at those who try to make a difference by helping to generate income and employment in the local market. Energy tourism represents just a niche like that and this niche is likely to expand in the nearest future $[35,36]$.

\section{Conclusions and implications}

All in all, it becomes clear that as energy is becoming a widely-discussed topic and the renewable energy sources are occupying growing share in the world's energy balance. Thanks to that, the importance and the popularity of less-known forms of tourism, such as the industrial tourism and energy tourism (which constitutes a special sub-set of industrial tourism mixed with adventure tourism) are increasing.

Our paper provided some examples of special-interest (SIT) tourism in general and energy tourism in particular in various parts of the world. It appears that now, in the postpandemic world, as the tourism worldwide is getting "smarter" and inclining to the individual (rather than mass) travel, the energy tourism is destined to develop rapidly. Travellers are going to visit dams and hydro stations, power stations, mines, nuclear plants as well as waterand windmills in large numbers showing their appreciation both for the cultural side of the attractions as well as for the energy aspect. In addition, it is clear that renewable energy projects such as wind parks, solar panel parks, and hydro power stations would also attract lots of visitors.

There are some cases when energy tourism can overlap with yet other forms of tourism such as dark tourism (for example, in the case of the Chernobyl nuclear power station that now serves as a tourist attraction, albeit a dangerous one, and which has been recently popularized by the HBO series of 2019) or fun tourism (for example, bungee jumping from 
dams). Nevertheless, it can be concluded that all combinations of tourism that include energy tourism are beneficial for the local economies and help to popularize energy research and sustainable behaviour. All of these might help to increase the social and public acceptance of renewable energy sources among the people and enhance the protection of the environment and tackling the global climate change.

\section{References}

1. F. Roxas, J. Rivera, E. Gutierrez, Current Issues in Tourism, 23(3), 280-296 (2020)

2. D. Streimikiene, E. Korneeva, Terra Economicus, 18(3), 182-193 (2020)

3. S. Soleimani, J. Bruwer, M. Gross, R. Lee, Current Issues in Tourism, 22(18), 22992314 (2019)

4. K. Kayumovich, F. Annamuradovna, S. Kamalovna, K. Bahodirovich, F. Kudratovna, Journal of Critical Reviews, 7(5), 366-369 (2020)

5. A. Chiabai, S. Platt, W. Strielkowski, Tourism Economics, 20(2), 263-277 (2014)

6. Y. Li, C. Hu, C. Huang, L. Duan, Tourism Management, 58, 293-300 (2017)

7. J. Abrhám, J. Wang, Journal of Social Sciences, Business and Economics, 6(1), 37-43 (2017)

8. V. Krajcik, A. Kljucnikov, E. Rihova, Marketing and Management of Innovations, 2, 108-117 (2019)

9. S. Ma, A. Kirilenko, S. Stepchenkova, Tourism Management, 77, 104021 (2020)

10. M. Bhuiyan, K. Zaman, A. Shoukry, S. Gani, M. Sharkawy, Sasmoko, A. Khan, A. Akhman, S. HishanEnergy Sources, Part B: Economics, Planning, and Policy, 13(1112), 463-474 (2018)

11. N. Mineeva, O. Makarova, Inland Water Biology, 11(3), 367-370 (2018)

12. D. Scott, Sustainability, 13(4), 1966 (2021)

13. S. Pan, M. Gao, H. Kim, K. Shah, S. Pei, P. Chiang, Science of the Total Environment, 635, 452-469 (2018)

14. A. Marin-Pantelescu, L. Tăchiciu, S. Căpuşneanu, D. Topor, Amfiteatru Economic, 21(52), 654-669 (2019)

15. I. Tyslová, J. Abrhám, Z. Horváthová, F. Rubacek, Terra Economicus, 18(2), 149-168 (2020)

16. D. De Grosbois, D. Fennell, Tourism Recreation Research, 1, 1-16 (2021)

17. P. Sharma, J. Nayak, Journal of Heritage Tourism, 15(1), 76-92 (2020)

18. G. Migale, J. Stimie, A. Brent, South African Journal of Industrial Engineering, 30(4), 102-117 (2019)

19. U. Shahzad, Z. Fareed, F. Shahzad, K. Shahzad, Journal of Cleaner Production, 279, 123806 (2021)

20. L. Dong, X. Tong, X. Li, J. Zhou, S. Wang, B. Liu, Journal of Cleaner Production, 210, $1562-1578$ (2019)

21. F. Bekun, A. Alola, S. Sarkodie, Science of the Total Environment, 657, 1023-1029 (2019)

22. Z. Li, Y. Song, A. Zhou, J. Liu, J. Pang, M. Zhang, Journal of Cleaner Production, 263, $121497(2020)$

23. A. Khan, S. Bibi, A. Lorenzo, J. Lyu, Z. Babar, Sustainability, 12(4), 1618 (2020)

24. U. Liebe, A. Bartczak, J. Meyerhoff, Energy Policy, 107, 300-308 (2017)

25. I. Cabelkova, W. Strielkowski, I. Firsova, M. Korovushkina, Energies, 13(7), 1742 (2020)

26. T. Sharpton, T. Lawrence, M. Hall, Renewable and Sustainable Energy Reviews, 126, 109826 (2020)

27. F. Guliyev, Energy Policy, 140, 111435 (2020) 
28. B. Goldstein, D. Gounaridis, J. Newell, Proceedings of the National Academy of Sciences, 117(32), 19122-19130 (2020)

29. S. Farmer, Rural Inventions: The French Countryside After 1945, Oxford University Press, 2020

30. M. Soland, S. Loosli, J. Koch, O. Christ, Energy Efficiency, 11(7), 1673-1688 (2018)

31. A. Balderas-Cejudo, I. Patterson, G. Leeson, International Journal of Gastronomy and Food Science, 16, 100152 (2019)

32. The Policy Times, https://thepolicytimes.com/extensive-analysis-of-the-global-nichetourism-industry (2019)

33. M. Kim, C. Lee, T. Jung, Journal of Travel Research, 59(1), 69-89 (2020)

34. S. Teixeira, J. Ferreira, A. Almeida, E. Parra-Lopez, Tourism Review, 74(4), 943-977 (2019)

35. B. Frantál, R. Urbánková, Current Issues in Tourism, 20(13), 1395-1412 (2017)

36. A. Jiricka, V. Wirth, B. Salak, U. Pröbstl, New Challenges for Tourism Promotion: Tackling High Competition and Multimedia Changes, International Tourism Research and Concepts. Erich Schmidt Verlag, Berlin, 85-103 (2012) 